\title{
Facing the Unknown: Healthcare Workers' Concerns, Attitudes and Burnout During the COVID- 19 Pandemic - A Mixed Methods Study
}

Keren Dopelt ( $\nabla$ dopelt@bgu.ac.il)

Ashkelon Academic College https://orcid.org/0000-0003-4922-4155

Osnat Bashkin

Ashkelon Academic College

Nadav Davidovitch

Ben-Gurion University of the Negev

Noam Asna

Barzilai Medical Centre Ashkelon

Research article

Keywords: Coronavirus wards, healthcare systems, social alienation, concerns, burnout, medical staff

Posted Date: October 5th, 2020

DOI: https://doi.org/10.21203/rs.3.rs-59465/v1

License: (c) (i) This work is licensed under a Creative Commons Attribution 4.0 International License.

Read Full License 


\section{Abstract}

Background: Medical staff, who care for patients at their own risk, are on the frontlines of the fight against COVID-19. The aim of this study is to describe the feelings and experiences of medical staff working in hospitals during the coronavirus crisis.

Methods: Data were collected as part of a mixed-methods study that included an online survey completed by 263 hospital staff members, as well as 10 semi-structured, in-depth interviews with doctors, nurses and medical technicians working on coronavirus wards.

Results: The survey findings revealed that respondents expressed extremely high rates of concern for family members and at a national level, but that they were less apprehensive about their own health and safety. At the same time, burnout was lower than the rates of concern. Nurses displayed more apprehension and burnout compared to medical staff in other professional roles. The in-depth interviews reinforced and supplemented the survey findings and deepened our understanding of the feelings of medical staff directly involved in coronavirus patient care.

Conclusions: The study's findings revealed the main concerns of hospital staff during the coronavirus crisis and deepened our understanding of the issues that require systemic attention in order to strengthen the mental resilience of hospital staff, in particular those working on coronavirus wards. The steps required to continue coping with and fighting the virus include the development of a mental and emotional support network for medical staff, to safeguard them and their health as they care for patients, and to provide ongoing psychosocial support.

\section{Background}

As of early September 2020, the novel coronavirus (SARS-CoV-2) has infected more than 30 million people worldwide and has caused the deaths of nearly a million people through the disease it causes, COVID-19. In Israel, over 171,000 people have been infected with the virus. (1) The spread of coronavirus presents difficult and complex challenges for healthcare systems, with various medical teams on the frontlines of the fight against it.

Reports from around the world have revealed that thousands of healthcare workers in hospitals across Europe have been infected with coronavirus. In Italy, as of April 2020, 12,252 medical staff were infected with the virus, 105 of whom have died. (2) It is possible that the true numbers of infections are higher than reported, since many medical staff have not been tested. (3). In Israel, more than 2,000 healthcare workers have been infected (1).

Assessing the mental health and perceptions of medical staff dealing with health crises is essential in gaining control over large-scale epidemics (4). Recent research in China has examined the immediate consequences of the fight against coronavirus on the mental health of medical staff (5). This study found that, of 2,299 medical staff, $30 \%$ reported symptoms of stress, $24 \%$ reported symptoms of anxiety, 
and $13.5 \%$ reported depression, with medical staff working directly with coronavirus patients having double the risk of suffering symptoms of anxiety and depression. A study conducted in Taiwan among 1,795 medical staff during the coronavirus crisis found that, although some respondents had previously experienced the SARS and MERS epidemics, $40 \%$ reported burnout and $78 \%$ reported high levels of anxiety. Most of the respondents who reported burnout worked in emergency units and treated coronavirus patients directly (6). In a similar study conducted in Turkey among 920 medical staff, $80 \%$ of respondents reported that the coronavirus crisis had affected their mental health, $71 \%$ of healthcare workers said that their departments had adequate levels of personal protective equipment (PPE) but expressed concern about its effectiveness, and a majority of respondents expressed high rates of emotional exhaustion (7).

Medical staff have expressed high levels of concern about being infected with coronavirus, as well as infecting family members, patients, and colleagues. A survey conducted among 4,357 medical staff in China revealed that $72.5 \%$ expressed concern for unprotected colleagues who might be infected, $63.9 \%$ expressed concern about infecting family members, and $52.3 \%$ expressed concern about the effectivity of protective measures (8). In many healthcare systems, medical staff do not undergo preparation for working in isolated coronavirus wards or for providing psychological support for isolated coronavirus patients (9). In India and Italy suicides among medical staff have been reported due to stress and mental strain $(10,11)$.

In Israel, since the outset of COVID-19's spread beyond the original outbreak in China, a strategy was implemented to prevent the spread of the disease (prevention), and later, after the virus arrived in Israel, to contain the spread (containment). These strategies provided more time to prepare for the opening of isolated inpatient wards in hospitals and to find quarantine solutions for patients in the community. Preparations included defined procedures for isolating and protecting medical staff and prevented widespread infection among healthcare teams, which could have led to a collapse of the healthcare system. However, responses to the psychological needs of medical staff working on the frontlines against the virus have yet to be tested. Safeguarding medical professionals, both in terms of protecting and preventing infection and preventing physical and mental burnout, is one of the most important principles when it comes to epidemics like COVID-19 (12). Examining the emotions of medical staff who are dealing with the epidemic is essential to improving the readiness of healthcare systems to continue fighting the virus.

\section{Methods}

The aim of this study was to examine perceptions and experiences around coping with the coronavirus crisis at a personal, family, national, and systemic level. This was a mixed-methods study, employing two types of tools: an online survey of hospital staff, followed by in-depth interviews with doctors, nurses, and medical technicians who worked on coronavirus wards during the crisis. 


\section{(a) Online survey of hospital staff}

\section{Research population and sample:}

The survey was conducted among staff at the Barzilai University Medical Center in Israel, which provides services to a population of approximately 500,000 people. The medical center has 567 beds and an additional 60 day-patient beds, and the facility employs around 2,000 staff members, including approximately 300 doctors. A dedicated coronavirus ward was established in the facility and operated from 8 March - 20 April 2020. The ward was set up within four days under the guidance of the Israeli Ministry of Health and was designed to treat 30 patients, including 10 on ventilators. Around 90 patients with varying degrees of illness severity passed through the ward during its period of operation. There were three teams working in the ward in 12-hour shifts to reduce exposure to other members of the hospital staff.

A link to the survey was sent to all staff members at the hospital, via an email from the Human Resources department. Within the convenience sample, 263 staff members from all sectors who completed at least $80 \%$ of the survey ( $13 \%$ response rate) were included in the study.

\section{Study tools:}

The online survey comprised 30 questions, which were composed by the authors and validated by 8 employees at a different hospital, to ensure that they were relevant to hospital staff during the crisis. The questionnaire developed for this study is provided as Additional File 1. The questionnaire included several sections, as per the following details:

1) Have you cared for/provided services to a coronavirus patient who had been tested, was in isolation, or had been infected?

2) Demographic details-gender, age, profession, family status, has children.

3) Concerns regarding the coronavirus crisis on a personal, family, systemic and national level-13 questions. Range of answers on the Likert Scale, ranging from (1) not at all concerned to (5) greatly concerned, plus the option "not relevant." Questionnaire reliability a $=0.88$. Sample question: "I am concerned about being infected with coronavirus / I am concerned about the rate of increase of the number of coronavirus patients in Israel."

4) Attitudes toward crisis management-3 questions. Range of answers on the Likert Scale, from (1) not at all to (5) to a very great extent. Questionnaire reliability $a=0.80$. A high score indicates more positive attitudes. Example question.: "I support the way in which the country has handled the crisis so far." 
5) Burnout-3 questions. Range of answers on the Likert Scale, from (1) not at all to (5) to a very great extent. Questionnaire reliability $\mathrm{a}=0.84$. A high score indicates a high level of burnout. Example question: "I feel worn out from dealing with the coronavirus crisis."

\section{Analysis of data:}

The data were processed anonymously in the SPSS v.25 program. Links between the variables were tested using the Pearson Correlation, variance between genders were tested using a $t$ test for independent samples, and variance between professions were tested using a one-way ANOVA.

\section{(b) In-depth interviews with staff who worked on coronavirus wards}

\section{The sample:}

Following the survey, 10 in-depth semi-structured interviews were conducted during May 2020 with 4 doctors (specialists in internal medicine, pulmonology, and intensive care), 4 nurses (initially from the internal medicine, neurology, cardiac intensive care, and pediatric intensive care wards), and 2 medical technicians. The interviewees comprised 2 males and 8 females. Two interviewees were single and living alone (one was in a relationship), and the remainder were married with children and even grandchildren. The sample was a deliberate sample combined with a snowball sample. The interviews were conducted by phone by a research assistant (MA student in Clinical Psychology), who was guided by the researchers. There was no relationship established prior to study commencement between the researchers and the interviewees. Every staff member we asked to be interviewed agreed, and the interviews lasted between 30-40 minutes. The questions were written by the researchers and dealt with the interviewees' experiences, concerns, and feelings regarding their work on the coronavirus ward. A pilot interview was conducted with a doctor who worked in Corona ward at another medical center. The interview guide developed for this study is provided as additional File 2.

\section{Data analysis:}

The interviewees signed a form agreeing to the recording and transcription of the interviews. The transcripts were not returned to participants for comment or corrections, and participants were not asked to provide feedback on the findings. The transcript files were entered into the ATLAS.ti v. 8 software for organizing and analyzing qualitative material by the two first authors. After an in-depth reading of the texts, the interviewees' statements were categorized into themes according to their content. The analysis was carried out according to the "grounded theory" qualitative worldview (13). 


\section{Results}

\section{a) Online surveys of medical center staff}

Table 1 shows the characteristics of the sample who responded to the online survey. As Table 1 illustrates, most respondents were female, partnered, and had children. Twenty-one percent provided services or treated coronavirus patients, and $11 \%$ spent time in isolation.

Table 1

Study sample characteristics $(n=263)$

\begin{tabular}{|lll|}
\hline Characteristic & N & $\%$ \\
\hline Male & 62 & 24 \\
\hline In a relationship & 192 & 73 \\
\hline No children & 35 & 13 \\
Children aged 0-10 & 98 & 37 \\
Children aged 11-18 & 90 & 34 \\
Children over 18 & 124 & 47 \\
\hline Provided services/treated coronavirus patients as part of their job & 56 & 21 \\
\hline Stayed in isolation & 28 & 11 \\
\hline Tested & 37 & 14 \\
No, test not required & 131 & 50 \\
No, even though a test was requested/required & 95 & 36 \\
\hline Role: & & \\
Physician & 40 & 15 \\
Nurse & 78 & 30 \\
Paramedic & 43 & 16 \\
Other (management and housekeeping, computing, auxiliary staff, laboratory) & 72 & 39 \\
\hline
\end{tabular}

Table 2 shows the relationships between the study variables. The results of the analysis reveal positive relationships between the respondents' concerns at a personal, family, system, and national level and burnout. Negative correlations were found between support for how the crisis was handled and between all these variables, except for national-level concerns and burnout. 
Table 2

Pearson correlations between the study variables $(n=263)$

\begin{tabular}{|c|c|c|c|c|c|}
\hline & $\begin{array}{l}\text { Family- } \\
\text { level } \\
\text { concerns }\end{array}$ & $\begin{array}{l}\text { National- } \\
\text { level } \\
\text { concerns }\end{array}$ & $\begin{array}{l}\text { System- } \\
\text { level } \\
\text { concerns }\end{array}$ & $\begin{array}{l}\text { Support for how the } \\
\text { crisis was managed }\end{array}$ & Burnout \\
\hline $\begin{array}{l}\text { Personal-level } \\
\text { concerns }\end{array}$ & $0.59 \star \star \star$ & $0.45^{\star \star \star}$ & 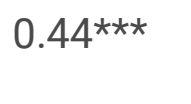 & 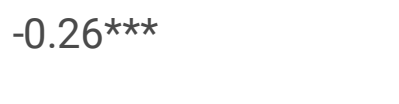 & $0.13^{*}$ \\
\hline $\begin{array}{l}\text { Family-level } \\
\text { concerns }\end{array}$ & & 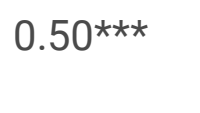 & $0.59 \star \star \star$ & $-0.19 \star \star$ & 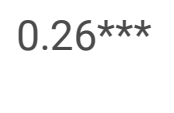 \\
\hline $\begin{array}{l}\text { National-level } \\
\text { concerns }\end{array}$ & & & $0.66^{\star \star \star}$ & NS & 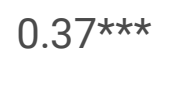 \\
\hline $\begin{array}{l}\text { System-level } \\
\text { concerns }\end{array}$ & & & & $-0.17^{\star \star}$ & 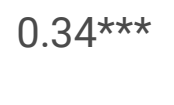 \\
\hline $\begin{array}{l}\text { Support for how the } \\
\text { crisis was handled }\end{array}$ & & & & & NS \\
\hline$p<0.05^{\star}, p<0.001^{\star *}, p$ & $0.001^{\star \star \star}$ & & & & \\
\hline
\end{tabular}

Table 3 shows variances between the professions in the study variables. The results show significant variances between professional roles across all variables, with the exception of burnout. Across all variables, doctors reported the lowest concerns, followed by nurses, and finally by respondents in other professional roles, who expressed the strongest concerns. 
Table 3

Results of a one-way ANOVA test of variances between doctors, nurses and other professions

\begin{tabular}{|c|c|c|c|c|c|c|c|c|}
\hline \multirow[t]{2}{*}{$\mathbf{P}$} & \multirow[t]{2}{*}{$F$} & \multicolumn{2}{|c|}{$\begin{array}{l}95 \% \text { Confidence Interval } \\
\text { for Mean }\end{array}$} & \multirow[t]{2}{*}{ SD } & \multirow[t]{2}{*}{ Mean } & \multirow[t]{2}{*}{$\mathbf{N}$} & & \\
\hline & & $\begin{array}{l}\text { Lower } \\
\text { Bound }\end{array}$ & $\begin{array}{l}\text { Upper } \\
\text { Bound }\end{array}$ & & & & & \\
\hline \multirow[t]{4}{*}{.001} & \multirow[t]{4}{*}{6.97} & 3.28 & 3.67 & .61 & 3.48 & 40 & Doctor & \multirow{4}{*}{$\begin{array}{l}\text { Personal-level } \\
\text { concerns }\end{array}$} \\
\hline & & 3.70 & 4.02 & .71 & 3.86 & 78 & Nurse & \\
\hline & & 3.81 & 4.02 & .65 & 3.92 & 145 & Other & \\
\hline & & 3.75 & 3.92 & .68 & 3.83 & 263 & Total & \\
\hline \multirow[t]{4}{*}{.001} & \multirow[t]{4}{*}{7.41} & 3.71 & 4.17 & .71 & 3.94 & 40 & Doctor & \multirow[t]{4}{*}{ Family-level concerns } \\
\hline & & 4.07 & 4.36 & .64 & 4.22 & 78 & Nurse & \\
\hline & & 4.26 & 4.41 & .46 & 4.33 & 145 & Other & \\
\hline & & 4.17 & 4.31 & .58 & 4.24 & 263 & Total & \\
\hline \multirow[t]{4}{*}{.000} & \multirow[t]{4}{*}{9.54} & 3.37 & 3.83 & .73 & 3.60 & 40 & Doctor & \multirow{4}{*}{$\begin{array}{l}\text { National-level } \\
\text { concerns }\end{array}$} \\
\hline & & 3.93 & 4.22 & .64 & 4.08 & 78 & Nurse & \\
\hline & & 4.03 & 4.27 & .72 & 4.15 & 145 & Other & \\
\hline & & 3.95 & 4.13 & .72 & 4.04 & 263 & Total & \\
\hline \multirow[t]{4}{*}{.035} & \multirow[t]{4}{*}{3.40} & 3.20 & 3.83 & .97 & 3.51 & 40 & Doctor & \multirow{4}{*}{$\begin{array}{l}\text { System-level } \\
\text { concerns }\end{array}$} \\
\hline & & 3.72 & 4.16 & .98 & 3.94 & 78 & Nurse & \\
\hline & & 3.79 & 4.11 & .95 & 3.95 & 145 & Other & \\
\hline & & 3.76 & 4.00 & .97 & 3.88 & 263 & Total & \\
\hline \multirow[t]{4}{*}{.049 } & \multirow[t]{4}{*}{3.04} & 2.70 & 3.44 & 1.16 & 3.07 & 40 & Doctor & \multirow{4}{*}{$\begin{array}{l}\text { Support for how } \\
\text { crisis was handled }\end{array}$} \\
\hline & & 3.23 & 3.69 & 1.00 & 3.46 & 78 & Nurse & \\
\hline & & 3.33 & 3.62 & .86 & 3.48 & 145 & Other & \\
\hline & & 3.29 & 3.53 & .96 & 3.41 & 263 & Total & \\
\hline \multirow[t]{4}{*}{.226} & \multirow[t]{4}{*}{1.50} & 2.52 & 3.09 & .88 & 2.81 & 40 & Doctor & \multirow[t]{4}{*}{ Burnout } \\
\hline & & 2.84 & 3.35 & 1.13 & 3.09 & 78 & Nurse & \\
\hline & & 2.71 & 3.04 & 1.00 & 2.87 & 144 & Other & \\
\hline & & 2.80 & 3.05 & 1.03 & 2.93 & 262 & Total & \\
\hline
\end{tabular}


An examination of variance between the genders found no difference in the level of personal and family concerns and level of burnout. However, women expressed higher national-level concerns than men (means $=4.16$ and 3.68 respectively, $\mathrm{p}<0.001, \mathrm{t}=4.69$ ) and greater system-level concerns (means $=4.03$ and 3.39 respectively, $p<0.001, t=4.68$ ). However, women expressed a higher level of support for the way the crisis was managed than men (means $=3.48$ and 3.18 respectively, $p<0.05, t=2.18$ ).

\section{b) Analysis of in-depth interviews}

Analysis of the interviews revealed 7 distinct themes:

\section{Theme 1: A sense of mission and responsibility as "going to war" to defend the homeland}

All of the interviewees expressed a sense of mission, which intensified during the coronavirus crisis. Particularly noticeable was the use of words describing a sense of going to war to defend the homeland: battlefield, front, fighters, danger to life, sacrifice: "The system functioned well. Like in a war. I felt like we were at war" (Interviewee 1, male).

The motif of "fighters on the frontlines" was repeated, in different words, in almost all the interviews. Like soldiers preparing for battle, the interviewees felt they were unable to refuse joining the coronavirus ward, despite the inherent risks: "There was no dilemma, actually. I didn't think that I could refuse. It was a job that needed to be done" (Interviewee 1, male).

Interviewee 6 (female) described the support she felt from the general population: "You know how exciting it is, the support of the population...how many people wanted to support us and help us. We felt that this wasn't just any old effort. It was clear that you were saving lives, even if you helped just one person, it's not just nothing. It's worth a lot."

\section{Theme 2: Concern for patients, for the family, and for all fellow citizens}

The interviewees often used the words: fear, danger, catastrophe. As a result of their sense of sacrifice, and their trust in the system to take care of their protection, they were less concerned about their own health and safety, and more concerned for the lives of patients, family members, their fellow citizens in general, and even for colleagues who worked outside the coronavirus ward and were not as protected as they were.

Interviewee 2, a female doctor, shared her concerns: "Of course, I was worried. And I wouldn't believe anyone who told me they weren't. I'm often exposed to infections. But here, we didn't know how it spread, 
what it is exactly...I was worried for my kids, for older people, for my mother for example."

The interviewees also talked about distancing from their families, mainly from their parents and grandchildren. Interviewee 7 (female) explained: "My relatives were worried that I would get infected and infect them."

There were also concerns about colleagues. Interviewee 8 (female) said that: "I wasn't scared for myself, because I knew that I was protected at all times. On other wards-you could be treating a patient and you don't know whether he has coronavirus, or whether you are protected or not. My parents are in their eighties, so of course I didn't see them."

At a national level, the interviewees voiced concerns about a second wave. Interviewee 6 (female) clarified the extent to which the sight of the patients impacted her concern over the potentially impending catastrophe: "Seeing it from inside, it's not the same as hearing about it from outside. When you see it from inside, it's something else. Fear. Fear about family. We see the danger. They say that doctors get used to death. That's not the case. It's not possible to get used to death. It felt like a fantasy movie about something catastrophic."

\section{Theme 3: Changes in routine work-the difficulties in "remote" treatment}

The interviewees described work on the coronavirus ward as very different from routine work in the hospital, even if that routine work involved being exposed to infection. The unique nature of COVID-19, a novel disease without evidence-based treatment, required continuous updates with colleagues in Israel and abroad, and the collating and updating of protocols and guidelines that did not previously exist. Furthermore, the fact that all professions had to wear PPE was a dramatic change. All the interviewees talked about the problematic nature of the many layers of PPE, which interfered with functioning, and especially impaired their ability to quickly reach distressed patients. Interviewee 1 (male) explained that: "The most stressful thing is that a patient can deteriorate without you being aware of it. And if you weren't wearing PPE, you weren't kitted up, and if something happened-it takes time for you to get kitted up, for the team to get ready." Interviewee 2 (female) added: "The PPE situation really disrupted patient care. It's really not comfortable, it's uncomfortable to breathe, it's uncomfortable to see, it's uncomfortable to talk. That, and there were patients who needed a lot of attention and we couldn't always be by their sides."

In addition to PPE, a further change was that of remote treatment. Interviewee 1 (male) said that: "You have to manage a patient's treatment remotely. You don't know what is going on with the treatment at any given time. There weren't cameras in all of the rooms."

Compounding this was the lack of human contact. Interviewee 7 (female) gave details: "We're usually in more contact with patients. Now on the coronavirus ward, we put on PPE and go in to see the patients, 
they don't know who we are, and there were a lot of patients who felt lonely. They were looking for some warmth. Their families weren't able to visit them."

\section{Theme 4: Burnout and the need for emotional support}

Some interviewees felt exhausted and drained. Interviewee 5 (female) said that: 'It's terribly hard to keep going for so long. Two months like this, and we are already exhausted. Although towards the end they brought in more teams, and that helped a lot."

In the wake of the burnout and stress, they expressed a need for an emotional preparation before entering the coronavirus ward, during and after the crisis. Interviewee 5 (female) explained: "I had moments where I wanted to talk about it with someone, but I didn't want them to feel sorry for me. You can buy the most sophisticated equipment in the world, but if you don't take care of the people who operate it, then it won't work."

In contrast, there were interviewees who did not feel burnout, either because they were accustomed to working under pressure, or because it was a new and different situation that aroused their interest. For example, Interviewee 3 (female) said: “I could have kept going for a long time, I didn't have a hard time. Our day-to-day jobs aren't easy either, we have to make decisions every single day. This is work under pressure, and human lives are in our hands"

\section{Theme 5: Feelings of loneliness versus challenge and empowerment}

The interviewees expressed feelings of loneliness and of being distanced from people. Interviewee 7 (female) said: "The people I know were scared to go near me. No, no, don't infect us, they said. But they didn't understand that they're infecting me more than I'm infecting them."

They felt that their colleagues distanced themselves from them and left them to fight alone on the frontlines:

It wasn't clear if anyone was going to replace us and what was going to happen to us. There was a feeling that everyone had fled and left us to fight on the frontlines alone...Many doctors avoided coming to the hospital at all. On the one hand you felt that you were doing something important and that you were saving lives in this difficult situation, but on the other, it was a bit frustrating to know that you'd been left alone on the battlefield and that not everyone was willing to lend a hand equally. (Interviewee 2, female)

Despite the loneliness and the fatigue, the interviewees felt empowered, and that they had made history as part of a unique, unusual experience, through continuous learning and mutual aid. Like interviewee 4 (female), who said: "Everyone had a unique experience, both because of the whole thing about entering 
an infected zone and because of the nature of the patients. The second that you feel you are part of a group and everyone is all together, like a single fist, then that really gives you strength." Interviewee 8 (female) explained that: "It empowered me. It really gave me something. It gave me more independence. Suddenly I discovered that I could manage and that I could be someone with a can-do attitude. I felt special." Interviewee 9 (female) added that: "It was a very, very intensive period. But really, really, it was an experience. In actual fact what we did made history."

\section{Theme 6: The functioning of the system}

The interviewees expressed a lack of trust regarding the management of the crisis. They agreed that the healthcare system was not prepared for such a pandemic outbreak, but that hospitals managed to make emergency preparations for the absorption of coronavirus patients. Nurses from all types of wards were trained in ICU respiratory patient care, a ward was established, advanced medical equipment, PPE, and drugs were purchased, teams were formed, and coronavirus patients began to be admitted. Interviewee 2 (female), explained:

The system wasn't prepared, and this is one of the things that was most stressful. Every day there was a new announcement. Every day they found new equipment. The lucky thing about this healthcare system is its human resources... The hospital manager worked really hard during that time period and came to support us. But I'm also disappointed that we were not ready, and we could have been ready, we were really lucky. But aside from luck, we had both the human resources and the abilities of those human resources.

\section{Theme 7: From heroics to routine: "once you've served your purpose, you can leave"}

The interviewees expressed a sort of frustration. Like fighters on a battlefield, they underwent an experience that was unique and empowering, but also intense and exhausting. During the crisis, everyone embraced and praised them, from proclamations from the healthcare system's top brass, down to hospital management and members of the public. However, when there was a lull, the support disappeared. Interviewee 2 (female) expresses all this:

I feel that with all the joy and support that we supposedly received during the coronavirus outbreak, everything went away, was forgotten, stopped. More at the level of the management and the managers, but also from the general population, the feeling is of "you've served your purpose, now leave." After everything is over, you expect that at least they would remember that you contributed a little bit more than other people and that you were willing to go a bit further than others. Very quickly we went back to seeing patients in the hallways. You need to think about medical staff on normal days too.

\section{Discussion}


The coronavirus epidemic has become one of the most serious health crises of recent decades. This study examined the perceptions and experiences of medical staff in a hospital in Israel around dealing with the coronavirus outbreak. The survey revealed that, out of the four levels of concern that were examined, personal concerns were the lowest among all respondents (mean $=3.83$ out of 5 ), while concerns about family were the most burdensome (mean $=4.24$ out of 5 ). Furthermore, we found that nurses expressed higher levels of concern than doctors across all four of the levels tested. Similar to the findings of the quantitative survey, analysis of in-depth interviews revealed that one of the major themes, expressed at high intensity, involved concerns and worries about family members, patients, and the wider population. These findings are consistent with previous studies $(14,15)$. Medical staff who participated in discussion groups at the start of the outbreak in the United States (14) noted that they did not expect a quick solution for every need that arose during this time. However, they did want to feel that their voices were being heard, and that their needs and expertise were an inseparable part of the discourse around the organizational and systemic preparations for dealing with the epidemic. Further, the respondents also noted the importance of expressions of gratitude from healthcare managers, which had a vital impact on reinforcing medical staff during the crisis. Similarly, in the in-depth interviews conducted as part of this study, medical staff expressed frustration and disappointment at the fact that they had not received recognition and appreciation from the system, after sacrificing their safety and endangering their health for the benefit of patients and colleagues. Reinforcing feelings of gratitude and empathy towards medical staff is critical during this period, since it helps mitigate staff's concerns around providing treatment in difficult and extraordinary circumstances on a daily basis (16).

In line with other recent studies $(7,8)$, interviewees in this study expressed concerns around PPE and its efficacy and use. Similar to the interviewees in this study, nurses in China, who were asked about their experiences during the coronavirus crisis, reported that wearing protective suits and other items of PPE for many hours caused physical distress that compounded the feelings of stress they experienced while working in isolation wards (5).

In addition to the use of PPE, coronavirus treatment protocol also included guidelines for remote care, a challenge that the interviewees in this study described as negatively impacting the relationship between medical staff and patients and causing feelings of alienation during treatment. The battle against coronavirus necessitates maintaining social distancing, isolating patients, and the donning of PPE during patient care, all of which pose substantial challenges to providing medical care to patients (17-19).

In line with previous studies, the findings of this survey indicated relatively low burnout rates (mean $=2.93$ out of 5). Nurses reported higher feelings of burnout than doctors $(20,21)$. Furthermore, we found that, as the personal, family, national, and systemic concerns of medical staff increased, so too did their feelings of burnout. Moreover, analysis of the in-depth interviews conducted for this study showed that the interviewees expressed feelings of burnout, exhaustion, and loneliness during the acute phase of the crisis, as well as mental stress. Subsequent to that, staff felt the need for a cocoon of emotional support. However, the interviews also revealed that feelings of empowerment, a strong sense of teamwork, and a sense of playing a significant medical role during this extraordinary period reinforced medical staff and 
evidently prevented burnout. A qualitative study conducted among 14 doctors and nurses in Hubei Province in China found that medical staff felt a strong sense of mission and responsibility to treat patients during the crisis. Despite concerns about infecting relatives with the virus and about unexpected dangers and workloads, medical staff focused on their responsibilities as professionals to fight the virus, demonstrated a sense of unity and professional dedication, and expressed a high sense of empowerment and self-efficacy in coping with the epidemic (5).

Researchers with experience in dealing with other epidemics like SARS and the H1N1 influenza outbreak, and with crises like the 9/11 terror attacks in the United States, have proposed three targeted principles for coping on a systemic/managerial level with an outbreak, which may affect the perceptions of medical teams (22). The first principle involves a focus on maintaining mental resilience via open, honest, and continuous communication between crisis managers and medical staff, gratitude, and offering a realistic and optimistic plan for coping. Second, teams should be provided with up-to-date and comprehensive information regarding the epidemic, which permits a sense of control while reinforcing the staff's professional skills to deal with the crisis. Lastly, ongoing support should be provided to medical staff, the expression of concerns and worries should be encouraged, a peer support program should be developed, and the mental and physical wellbeing of staff should be maintained. There is no doubt that, during times of crisis like the current pandemic, health service leaders must maintain direct, ongoing links with medical staff, to collaborate on decision-making and the development of treatment strategies, to continuously monitor staff's physical and mental health, and to make tools and resources for support available to them (23).

This study has several limitations. First, the survey was conducted among a relatively small sample of medical staff taken from a single hospital. A large-scale sample, taken from several hospitals, is required in order to reinforce these findings. Second, within this study, we did not carry out any follow-up or evaluation of support services that were provided to healthcare staff during the coronavirus crisis. In addition, this study did not include a psychological assessment of aspects such as depression and anxiety using accepted psychological evaluation tools.

\section{Conclusions}

The results of this mixed-methods study shed light onto the main concerns of frontline medical staff during the coronavirus crisis and illustrate in depth the main issues that require immediate systemic attention in order to reinforce medical staff's mental resilience in times of crisis. Health services need a good understanding of concerns felt by medical staff, and what motivates those concerns. Furthermore, health services must acknowledge these concerns and develop strategies to address the sources of stress and worry. Conversations with medical staff working directly with coronavirus patients may reduce their anxiety and could help shed light on the actions required to support and reinforce staff (15).

To improve the preparedness of health services to cope with the ongoing coronavirus pandemic, various steps are required. These include developing a mental and emotional support network for frontline 
medical staff, ensuring their protection and health as they care for patients, and providing continuous psychosocial support. These steps will help safeguard the human resources that are critical to winning the battle against the novel virus that is spreading around the world. In addition, further examination and tracking of medical staff concerns and needs will enable developing an effective response plan for future health crises. As Israel is facing a much larger second wave, there are signs that current burden on medical staff is even heavier, especially as hospitals are now taking care of both corona and non-corona illnesses, unlike in the first wave when ministry of health demanded the reduction of elective activities.

\section{Abbreviations}

Covid-19: Coronavirus disease 2019

PPE: Personal Protective Equipment

ANOVA: Analysis of variance

\section{Declarations}

\section{Ethics approval and consent to participate}

Ethical approval of the current study was obtained from the Ethics Comity, Ashkelon Academic College. The permission to conduct the research was obtained from the authorities in the study settings. All participants were informed of the aims of the study and their participation was on a voluntary basis. Interviewees signed an informed consent form. As for the confidentiality of the information, the participants were not required to write their identifying information in the questionnaire. Identifying details of the interviewees were not published. The participants had the right to refuse participation or withdraw from the study.

\section{Consent for publication}

Not applicable.

\section{Availability of data and material}

The data that support the findings of this study are available from the corresponding author.

\section{Competing interests}

The authors declare that they have no competing interests. 


\section{Funding}

Not applicable. The project has not received any financial support or grant from any research or academic institutes.

\section{Authors' contributions}

$\mathrm{KD}, \mathrm{OB}, \mathrm{ND}$ and NA contributed substantially to the conception and the design of the study. $\mathrm{OB}$ and $\mathrm{KD}$ carried out data collection and statistical analysis and analysis of the in-depth interviews. KD, OB, and NA interpreted the data. KD, OB, ND and NA drafted and revised the manuscript. All authors reviewed and approved the final manuscript.

\section{Acknowledgements}

Not applicable

\section{References}

1. Israel Ministry of Health- Corona Updates [Internet]. Govextra.gov.il. 2020 [cited 4 August 2020]. Available from: https://govextra.gov.il/ministry-of-health/corona/corona-virus/

2. Istituto Superiore di Sanità. Sorveglianza integrata COVID-19: i principali dati nazionali [Internet]. iss.it. 2020 [cited 4 August 2020]. Available from: https://www.epicentro.iss.it/coronavirus/sars-cov2-sorveglianza-dati

3. Day M. COVID-19: four-fifths of cases are asymptomatic, China figures indicate. BMJ 2020;369:m1375. Available from: doi:10.1136/bmj.m1375

4. Liu, YH, Yang, HN, Liu, H, Wang, F, Hu, LB, Zheng, JC. Medical rescue of China National Earthquake Disaster Emergency Search and Rescue Team in Lushan earthquake. Zhonghua wei zhong bing ji jiu yi xue. 2013;25:265-7. Available from: doi: 10.3760/cma.j.issn.2095-4352.2013.05.004. Chinese.

5. Liu Q, Luo D, Haase J, Guo Q, Wang X, Liu S et al. The experiences of health-care providers during the COVID-19 crisis in China: a qualitative study. Lancet Glob Health. 2020;8(6):e790-e798. Available from: doi:10.1016/S2214-109X(20)30204-7

6. Sung C, Chen C, Fan C, Su F, Chang J, Hung C et al. Burnout in Medical Staffs During a Coronavirus Disease (COVID-19) Pandemic. SSRN [preprint] 2020 [posted 2020 Jun 09] Available at: SSRN: https://ssrn.com/abstract=3594567 or http://dx.doi.org/10.2139/ssrn.3594567

7. Sahin T, Aslaner H, Eker OO, Gokcek MB, Dogan M. Effect of COVID-19 pandemic on anxiety and burnout levels in emergency healthcare workers: a questionnaire study. Research Square [preprint]. 2020 [posted 2020 June 04]. Available from: org/10.21203/rs.3.rs-32073/v1 
8. Dai Y, Hu G, Xiong H, Qiu H, Yuan X. Psychological impact of the coronavirus disease 2019 (COVID19) outbreak on healthcare workers in China. MedRxiv [preprint]. 2020 medRxiv 2020.03.03.20030874 [posted 2020 Mar 06]. Available from: https://doi.org/10.1101/2020.03.03.20030874

9. Lima C, Carvalho P, Lima I, Nunes J, Saraiva J, de Souza R et al. The emotional impact of Coronavirus 2019-nCoV (new Coronavirus disease). Psychiatry Res. 2020;287:112915. Available from: doi:10.1016/j.psychres.2020.112915

10. Goyal K, Chauhan P, Chhikara K, Gupta P, Singh M. Fear of COVID 2019: First suicidal case in India! Asian J Psychiatr. 2020;49:101989. Available from: doi:10.1016/j.ajp.2020.101989

11. Montemurro N. The emotional impact of COVID-19: From medical staff to common people. Brain Behav Immun. 2020;87:23-24. Available from: doi: 10.1016/j.bbi.2020.03.032

12. Cook T. Personal protective equipment during the coronavirus disease (COVID) 2019 pandemic - a narrative review. Anaesthesia. 2020;75(7):920-927. Available from: doi:10.1111/anae.15071

13. Charmaz K. Constructing grounded theory: A practical guide through qualitative analysis. Thousand Oaks, CA: Sage; 2006.

14. Shanafelt T, Ripp J, Trockel, M. Understanding and addressing sources of anxiety among health care professionals during the COVID-19 pandemic. Jama. 2020;323(21), 2133-2134. Available from: doi:10.1001/jama.2020.5893

15. Adams JG, Walls RM. Supporting the health care workforce during the COVID-19 global epidemic. Jama. 2020; 323(15):1439-1440. Available from: doi:10.1001/jama.2020.3972

16. Singer T, Klimecki OM. Empathy and compassion. Curr Biol. 2014;24(18):R875-R878.

17. Wright JH, Caudill R. Remote Treatment Delivery in Response to the COVID-19 Pandemic. Psychother Psychosom. 2020;89(3):130-132. Available from: doi:10.1159/000507376

18. Wakam GK, Montgomery JR, Biesterveld BE, Brown CS. Not dying alone-modern compassionate care in the Covid-19 pandemic. N Engl J Med. 2020; 382(24), e88. Available from: doi: 10.1056/NEJMp2007781

19. Hollander JE, Carr BG. Virtually perfect? Telemedicine for Covid-19. N Engl J Med 2020;382:16791681. Available from: doi: $10.1056 /$ NEJMp2003539

20. Pappa S, Ntella V, Giannakas T, Giannakoulis VG, Papoutsi E, Katsaounou P. Prevalence of depression, anxiety, and insomnia among healthcare workers during the COVID-19 pandemic: A systematic review and meta-analysis. Brain Behav Immun. 2020;88:901-907. Available from: doi:10.1016/j.bbi.2020.05.026

21. Li Z, Ge J, Yang M, Feng J, Qiao M, Jiang R et al. Vicarious traumatization in the general public, members, and non-members of medical teams aiding in COVID-19 control. Brain Behav Immun. 2020;88:916-919. Available from: doi:10.1016/j.bbi.2020.03.007

22. Wu AW, Connors C, Everly GS Jr. COVID-19: Peer Support and Crisis Communication Strategies to Promote Institutional Resilience. Ann Intern Med. 2020;172(12):822-823. Available from: doi:10.7326/M20-1236 
23. Williamson V, Murphy D, Greenberg N. COVID-19 and experiences of moral injury in front-line key workers. Occup Med (Lond). 2020;70(5):317-319. Available from: doi:10.1093/occmed/kqaa052

\section{Supplementary Files}

This is a list of supplementary files associated with this preprint. Click to download.

- COREQchecklist.docx

- File2InterviewGuideConsentForm.docx

- File1Questionnaire.docx 